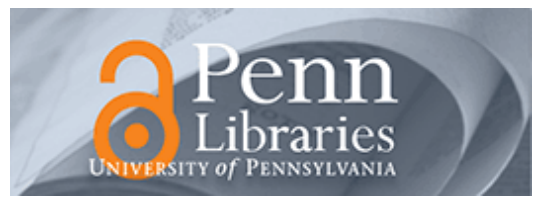

University of Pennsylvania

ScholarlyCommons

Management Papers

Wharton Faculty Research

$11-2006$

\title{
Stages of the Recruitment Process and the Referrer's \\ Performance Effect
}

Valery Yakubovich

University of Pennsylvania

Daniela Lup

Follow this and additional works at: https://repository.upenn.edu/mgmt_papers

Part of the Business Administration, Management, and Operations Commons, and the Human Resources Management Commons

Recommended Citation

Yakubovich, V., \& Lup, D. (2006). Stages of the Recruitment Process and the Referrer's Performance Effect. Organization Science, 17(6), 710-723. http://dx.doi.org/10.1287/orsc.1060.0214

This paper is posted at ScholarlyCommons. https://repository.upenn.edu/mgmt_papers/113

For more information, please contact repository@pobox.upenn.edu. 


\title{
Stages of the Recruitment Process and the Referrer's Performance Effect
}

\begin{abstract}
Although the existing theory predicts that a referral's chances of being hired increase with the job performance of the referrer, no empirical evidence is available to support this claim. To address this discrepancy, we decompose the recruitment process into objective selection, subjective selection, and self-selection and theorize that the likelihood of passing a particular recruitment stage increases with the performance of the referrer under objective selection and self-selection, but remains undetermined at a stage of subjective selection. Our analysis of unique comprehensive data on online recruitment of sales agents in a virtual call center supports these arguments. The effectiveness of personnel as a recruitment channel varies with the type of the recruitment stage and performance of the referrer. When the firm evaluates candidates by an objective criterion, the advantage of a referral increases with the performance of his or her referrer; those referred by relatively high-performing workers are significantly better than the applicants who learned about the job from Internet ads. When job candidates self-select into the next stage of the online application process, the referral of any agent is more likely to continue than a nonreferral, and this likelihood increases with the performance of the referrer. On a subjective stage, the outcome is contingent on the intricacies of the recruitment process. In our case, an applicant's chances of being hired increase with the performance of his or her referrer because the firm rejects the referrals of low-performing workers at a higher rate than it does nonreferrals, while it treats equally the referrals of high-performing workers and nonreferrals. The study's contributions to the literature on social networks in labor markets are discussed.
\end{abstract}

\section{Keywords}

labor markets, social networks, virtual recruitment, hiring through referrals, contingent workers

Disciplines

Business Administration, Management, and Operations | Human Resources Management 


\title{
Recruitment to a Virtual Organization: Does a Referral Matter?
}

\author{
Valery Yakubovich \\ Daniela Lup \\ University of Chicago
}

Direct correspondence to: Valery Yakubovich, valery@ChicagoGSB.edu. 


\begin{abstract}
We explore network recruitment in a new Internet-based organizational setting characterized by arm's-length relationships between the employer and workers and heightened competition among workers. Personal contacts remain a salient recruitment channel, although their effectiveness varies with the type of the recruitment stage: selfselection, objective selection, and subjective selection. We argue that on a self-selection stage, where a job candidate decides herself whether to proceed to the next stage of the on-line application process, referrals of current agents are more likely to follow through. On an objective selection stage, where the firm evaluates candidates by an objective criterion, the advantage of a referral increases with the performance of her referrer; the referrals of relatively higher-performing workers do better than the applicants referred by inferior candidates. Finally, on a subjective stage, where HR personnel make a judgment about a candidate's qualifications, the outcome is contingent on the intricacies of the recruitment process. In our case, an applicant's chances increase with the performance of her referrer, but primarily because the firm rejects the referrals of worse-performing candidates rather than gives an advantage to those of better performing ones. The analysis utilizes unique comprehensive data on on-line recruitment of sales agents in a virtual call center (VCC). The study's contributions to the literature on social networks in labor markets are discussed.
\end{abstract}




\section{INTRODUCTION}

Over the last decade, scholars of organizations have been witnessing the rapid proliferation of a "virtual" organization characterized by the geographic dispersion of its employees who rely on electronic means to perform their functions and communicate with each other (for review, see Burris 1998, DeSanctis and Monge 1999). Physical separation is often accompanied by lateral contractual relationships between the employer and employees (Jarillo 1993). Proponents of the virtual organization emphasize its flexibility and responsiveness to rapidly changing market conditions; critics see a weakening of the organizational identity, worker loyalty, and social cohesion that are key determinants of performance (Davidow and Malone 1992). While such questions are debated, the number of workers who experience the virtual organizational form on a regular basis rapidly grows. According to Gartner Group's estimate, the number of teleworkers, defined as those who work from home at least 8 hours a week, more than doubled, from about 5 million in 1999 to 12 million in 2005 , and they currently comprise $9.2 \%$ of the labor force (Jones 2005).

Although these changes have direct implications for recruitment, very little is known about the ways in which virtual organizations recruit workers, in particular, about the role of recruitment through social networks, the most common and well-studied channel in traditional settings. The received theory posits that recruitment is an inherently social process in which personal relationships among employers, job seekers, and intermediaries play a leading role, providing intensive hard-to-measure information, attracting candidates who would not apply through formal labor market channels, and securing a smoother adjustment and more effective training. Job candidates referred by the firm's current workers are more likely to survive the selection process and perform on the job because they possess more appropriate observable and 
unobservable characteristics, have a deeper understanding of the job's requirements and the firm's culture, and receive informal help with training and socialization (for review of the literature, see Fernandez, Castilla, and Moore 2000; Granovetter 1995; Marsden and Goorman 2001). Estimations show that employers' investment in the social capital of their employees in the form of bonuses for successful referrals deliver nontrivial economic returns (Fernandez, Castilla, and Moore 2000). Management textbooks support such practices because referrals "are more satisfied, productive, and likely to remain" with the firm (Baron and Kreps 1999: 342).

These arguments either explicitly of implicitly assume that workers strongly identify themselves with their organization and are loyal to it. If this were not the case, they would consider referrals exclusively as an opportunity to help their family and friends while treating any concerns about the abilities and qualifications of job candidates as the employer's business. Therefore, to the degree in which the virtual organization undermines workers' organizational identity and establishes an arm's-length employment relationship, recruitment through referrals becomes problematic. In addition, insecure employment and the need to constantly defend one's position against internal and external competitors creates a disincentive for referring and training strong candidates who can threaten the referrer herself.

Inevitable changes in the technology of the recruitment process compound these problems further. So far, the well-familiar face-to-face interview remains an integral part of recruitment in most organizations. However, as the practice of outsourcing whole business functions such as sales and customer support grows, performing the same functions in geographically dispersed locations is becoming widely accepted and even economically necessary. Remote recruitment is a part of this process and the Internet appears to be the most appropriate medium for it. 
On one hand, the Internet offers a promising arena for matching employers and workers, reduces for them the costs of seeking each other, and provides effective tools for testing and assessing job candidates. On the other hand, it heightens the problem of adverse self-selection, since less able candidates, who in the past would not bother to apply, find it very easy to do electronically. Autor (2001) predicts that in response to adverse self-selection, employers' reliance on personal contacts will become even more pervasive. However, if in a virtual organization referrers are not concerned with their protégés' fit to the job, they will exacerbate adverse selection rather than prevent it.

We argue that under such circumstances, referrals' likelihood of advancing successfully through the recruitment process relative to nonreferrals is contingent on the selection mechanism. Only referrals of relatively high-performing agents are actually better when an objective selection criterion is systematically applied across all applicants, because of social homophily between the referral and referrer and information and help provided by the latter to the former. However, on average any referral is more likely to self-select herself into the job than a nonreferral which points to adverse self-selection driven by referrals' stronger motivation and knowledge of the intricacies of the recruitment process. The important issue is whether HR personnel can control self-selection by identifying and rejecting poor matches via subjective selection.

Our analysis of unique comprehensive data on on-line recruitment of sales agents in a virtual call center (VCC) generally supports these arguments. Personal contacts remain a salient recruitment channel, although their effectiveness varies with the type of the recruitment stage: self-selection, objective selection, and subjective selection. When job candidates self-select into the next stage of the online application process, referrals of current agents are more likely to 
continue. When the firm evaluates candidates by an objective criterion, the advantage of a referral increases with the performance of her referrer; only the referrals of relatively higherperforming workers are significantly better than the applicants who learned about the job from Internet ads. Finally, on a subjective stage, where HR personnel make a judgment about a candidate's qualifications, the outcome is contingent on the intricacies of the recruitment process. In our case, an applicant's chances increase with the performance of her referrer, but primarily because the firm rejects the referrals of worse-performing candidates rather than gives an advantage to those of better performing ones.

The paper is organized as follows: first, we present relevant theoretical arguments and formulate two testable propositions. Next, we describe the empirical setting, which is substantially different from those in which similar studies have been conducted. The third section is devoted to a detailed description of our data and research methodology. After providing empirical findings, we summarize them, highlight their limitations, and discuss their implications for labor markets and our future research agenda.

\section{THEORETICAL APPROACH}

A number of recent case studies of organizations carefully document the role of referrals in recruitment. We learn that by and large referrals enjoy advantage over nonreferrals due to their propensity to present more appropriate résumés, to apply when market conditions are more favorable, and to rely on the reputation, influence, and support of their sponsors (Fernandez and Weinberg 1997; Fernandez, Castilla, and More 2000). Not surprisingly, access to potential referrers and the ability to mobilize them become major factors in hiring and, for example, explain hiring rate differentials among ethnic groups (Petersen, Saporta, and Seidel 2000). 
By relying on workers' social networks, employers economize on hiring costs and share these savings with the very same workers in the form of bonuses for successful referrals (Fernandez, Castilla, and More 2000). Such formal referral programs proliferate despite the lack of evidence that referrals are actually better workers. Castilla (2005) provides the first credible evidence that referrals are more productive than nonreferrals right after the hire, but the advantage disappears in the long run and, moreover, turns into a disadvantage if the referrer quits the firm. Neckerman and Fernandez (2003) point to multiple contingencies that may shape the impact of referrals on performance, including the firm's organizational structure. It is puzzling, however, that the same contingencies do not condition the recruitment process as well; referrals' advantage consistently appears at all its stages in the studies currently available.

"Virtuality" is a new organizational contingency that sheds light on the variation in the impact of referrals on both the recruitment process and performance. Being Internet-based, virtual recruitment requires a more careful delineation of recruitment stages and leaves an extensive electronic trail. These two factors make possible a classification of recruitment stages into a set of distinctive categories and enable a comparison of the referral effect across them.

Any recruitment process typically consists of a number of stages, which we classify into three types: self-selection, objective selection, and subjective selection. On stages of selfselection, applicants themselves decide whether to proceed further or not; the decisions to submit an application and accept an offer are the most common examples. On stages of objective selection, an employer consistently applies the same metrics to all candidates and automatically makes a decision to move a person to the next stage if a predetermined target is met. Various tests with a minimum passing score are the primary example. Subjective selection is 
characterized by relatively vague and idiosyncratic considerations, with the offer-making stage being a good example.

In a "real" organization, objective selection in the form of tests and other metrics is rarely separated into a distinct stage but lumped together with subjective considerations on the stage of an interview or job offer. Therefore, the literature typically deals with subjective selection on the interview and job offer stages as well as various kinds of self-selection. The transition to virtual organization, in general, and virtual recruitment, in particular, creates both the opportunity and the need for clear distinctions among the three types of selection. The opportunity derives from the ability of HR departments to administer tests and other standard recruitment procedures online. Computers are perfectly capable of measuring the outcomes of such procedures and employers can delegate to them standardized decisions. If they do, the procedure becomes a distinctive selection stage. The need to distinguish among the three types of selection stages stems from the impersonal nature of virtual recruitment. Since HR personnel do not monitor and guide applicants until late in the process, the process itself has to be well structured and easy to navigate. The clear assignment of decision-making to the applicant, computer, or an HR person helps achieve this goal.

We argue that the role of referrals varies by the type of the recruitment stage. At a selfselection stage, an applicant herself makes the decision whether to proceed further. The employer has few opportunities to encourage desirable candidates or discourage undesirable ones. The literature argues that this is one reason why an employer benefits from referrals in the traditional setting: the referrer turns into a gatekeeper because she cares about her reputation with the employer, knows the candidate's shortcomings, and therefore is in a good position to dissuade her from applying, if necessary. The virtual setting undermines this rationale, since an 
arm's-length relationship between the employer and referrer greatly diminishes the latter's reputational concerns. At the same time, by refusing to promote a relative or friend who is less qualified, the worker loses reputation with her personal network, within which help with getting a job is part of routine reciprocal exchanges enforced by social norms such as "a friend in need is a friend, indeed." Thus, a network member's needs drive the referrer's actions whether the member is qualified to do the job or not. If a network member decides to apply, the referrer will support him and help him overcome the hurdles of any self-selection stage:

PROPOSITION 1. A referral is more likely than a nonreferral to complete a self-selection stage of the recruitment process.

The literature offers a few arguments that explain why referrals should be better than nonreferrals by objective measures. Let us start with the oft-cited social homophily argument: because people tend to socialize with others similar to them and referrers have survived a prior screening process, their referrals are better qualified than nonreferred applicants (Fernandez, Castilla, and Moore 2000; McPherson, Smith-Lovin, and Cook 2001; Montgomery 1991, Mouw 2003; Myers and Shultz 1951, Rees and Shultz 1970; Ullman 1966). The argument is traditionally formulated in terms of observable socio-demographic characteristics such as gender, age, education, social class, religion, as well as behaviors and values (for review, see McPherson, Smith-Lovin, and Cook 2001). Empirical evidence does show that referrals and their referrers exhibit above-chance levels of homophily on individual characteristics relevant to recruitment (Fernandez, Castilla, and Moore 2000) but it does not show that referrers' characteristics can predict referrals' performance. The latter is not surprising: since socio-demographic 
characteristics usually explain little about the labor market outcomes of their holder, it is hard to expect them to be informative about their holder's referral.

In addition, the homophily argument in its current form implicitly assumes that employers do not make mistakes in hiring or, if they do, they never learn from them. As a result, if a wrong person has been hired, his future referrals, who are similar to him, will be hired as well. However, underperforming workers do exist and, according to the very same homophily principle, their referrers cannot be that good. To address these inconsistencies, we suggest a weak homophily argument which only asserts that the advantage of a referral over a nonreferral increases with the fit between the referrer and the job, assuming it is the same job the referral applies to. ${ }^{1}$ The argument does not imply that referrals are always better than nonreferrals. In fact, it allows for the possibility that under some circumstances even referrals of the very best performers may be indistinguishable from nonreferrals. However, it does suggest monotonicity in a referral's advantage: if referrer A's protégé is better than a nonreferral, the same should be the case for an average referrer better than $\mathrm{A}$.

The second widely accepted argument in favor of referrals is often called a better match argument. It builds on the ability of referrers to equip both employers and job candidates with detailed, sensitive, and non-standard information about each other and thereby improve the overall quality of matches (Rees 1966, Granovetter 1974). Useful bits of information may come not only from what referrers say but also from what they do. Neckerman and Fernandez (2003: 304-305) describe a referral program that allows referrers to choose at the time of making the

\footnotetext{
${ }^{1}$ In fact, one difficulty with an accurate test of the homophily argument is that referrers more often than not hold jobs different from the ones they refer to. Fernandez and Castilla (2001) find that workers with prior experience on a job are more likely to refer candidates to that job. However, they do not have access to performance records from previous jobs which may it difficult to evaluate the homophily argument.
} 
referral whether to claim a referral bonus or not. Two-thirds of the referrers did and their referrals had a significantly lower turnover rate within the 18 months period after the hire, while the referrals of those who did not claim the bonus had the same turnover rate as nonreferrals. Thus, referrers have a pretty good idea about the quality of their protégés.

In a virtual setting, the arm's-length relationship between an employer and workers may impede information transfers from the latter to the former. However, firms and their job candidates can still benefit from the candidates' improved knowledge of the job opportunity due to their contacts with the referrers. As in the case of homophily, better referrers should provide better information to their protégés.

Finally, the conventional theory posits that employers benefit from referrals in the long run due to socialization. Having a link to the firm from the beginning helps the newcomer access resources, receive informal training, and form ties to other workers (Fernandez, Castilla, and Moore 2000). A hidden assumption here is that the spirit of collaboration prevails in organizations. We know, on the other hand, that organization members compete against each other as well (Pfeffer and Sutton 2000) and sales are one of the most competitive lines of business. Therefore, getting a new strong competitor is not necessarily in a referrer's best interests; however, this becomes less of a concern, the stronger the referrer's performance. Even if a relatively strong referrer sponsors a weaker candidate, that candidate may still be marginally better than nonreferrals. Employers should worry, however, if the referrer is a weak performer. In this case, the competition argument implies that she will sponsor a weaker and, more often, unqualified candidate. To summarize our discussion, a referral's objective superiority over a non-referral should be a monotonically increasing function of the referrer's performance: 
PROPOSITION 2. On an objective selection stage of the recruitment process, a referral's advantage over a nonreferral increases with the performance of the referrer.

While the outcomes of self-selection and objective selection are susceptible to predictions regarding the effect of the referrer's performance, the outcome of subjective selection is difficult to determine because it is often guided by additional considerations unrelated to the individual performance directly. It may be influenced by the very fact that a candidate is referred, if the decision maker takes that fact as a signal of the advantages we discussed earlier, even if the advantages themselves are not there. For example, Fernandez and Weinberg (1997) find strong empirical evidence of the employer's preference for referrals vis-à-vis other candidates after the quality of résumés, including relevant socio-technical characteristics, are taken into account. The authors speculate that by doing so the employer rewards the loyalty of its workers and gives them a sense of empowerment.

At the same time, there are circumstances under which an employer is disinclined to hire referrals. If workers' influence is too strong, the employer may want to prevent their further empowerment and therefore will try to avoid hiring through referrals (Manwaring 1984). It may be the case that management is unhappy with the current labor force for one reason or another and wants a change. For a virtual organization, another possible consideration is the geographic distribution of its labor force. For example, it is beneficial to have customer service agents dispersed across various time zones to ensure uninterrupted service around the clock. This is particularly critical when agents work as independent contractors, since they choose their working hours themselves. Referrers bring candidates from their own localities and thereby limit geographic diversification. 
Thus, it is impossible to predict in general terms the effect of referrals on subjective stages of the selection process; the knowledge of the intricacies of a specific setting is a must. We describe our setting in the next section.

\section{EMPIRICAL SETTING}

\section{The Virtual Call Center (VCC)}

We analyze the recruitment of sales agents in a Virtual Call Center (VCC). The Center handles for its clients, which are vendors of various products, inquiries and purchases that are generated from infomercials broadcast on TV networks. Its entire sales force consists of independent contractors who work from home and process orders over the Internet. They are free to determine their work schedules and set their own hours. The pay is assessed at a fixed rate per minute of time on the phone with callers and typically varies between $\$ 8-15$ for an hour of work, which includes both time spent on the phone with callers and idle time spent waiting for calls. The average utilization rate, the percentage of the work time spent on the phone with callers, is about $50 \%$ in the period we study.

Computer-assisted training of new recruits takes place on-line without any coaching by the firm's personnel. In its instructions to potential job applicants, the firm explicitly states that it does not provide compulsory training beyond the recruitment process and seeks applicants who are already capable of providing a professional level of services.

To motivate performance, the firm makes sales agents compete against each other. The VCC continuously monitors performance by individual product and uses this data to assign agents their positions in the queue for receiving calls. Better performers have priority, regardless

of the number of calls they have already processed. Remuneration is determined entirely by the 
time an agent spends on the phone with callers and thereby is closely linked to her priority in the queue.

The workers' status as independent contractors, their work-at-home arrangement, a highly competitive environment and transparent performance measures closely linked to rewards all point to an arm's-length employment relationship. The VCC purposefully shapes it that way by emphasizing that it helps its agents develop and sustain their own home-based businesses. Whenever the conventional descriptions of the organizational structure do not reflect the arm's length relationship, they are promptly replaced. For example, initially the VCC assigned to each agent an agent supervisor who was supposed to monitor her performance, provide help, and resolve conflicts. When it was noticed that the term "agent supervisor" is incompatible with a market-like relationship, it was replaced by "agent facilitator."

\section{The Recruitment Process at the VCC}

The VCC does not have a pre-set number of vacancies but strives to ensure that the number of agents and their work schedules correspond to the demand for their services. To send a clear signal that it does not hire a permanent labor force and instead contracts free agents to conduct its business, the VCC refers to its recruitment process as "certification." The certification process consists of multiple stages. To prepare for them, an applicant registers on the VCC's website and provides her background information: education, Spanish speaking skills, years of experience in sales and call centers, and so forth. 
On Stage One, the testing stage, an applicant decides whether to take reading and logic tests $^{2}$ and if she fails even one of them, her application is rejected and she may not proceed further. The test is administered entirely on the Web with the computer calculating the score and making the decision. Thus, according to our classification, Stage One consists of two analytically separate sub-stages of self-selection and objective selection: an applicant self-selects into taking the tests while the computer determines whether she passes them according to an objective criterion.

Next, an applicant decides whether or not to take a voice test. Although HR personnel do not evaluate results immediately, but rather later, together with the whole application package, the job candidate cannot proceed further without taking this test and therefore we put taking the voice test into a separate Stage Two. According to our classification, it fits into the self-selection category.

With the voice test taken, a job candidate's application package is complete and ready for screening, and subsequent approval or denial. During the screening process the HR personnel review the materials submitted, listen to the voice test recording, and conduct a phone interview, although the latter does not always take place. This is where the recruitment process has a bottleneck. HR personnel are physically incapable of processing all the applications in a timely manner and have to establish some priority. The absence of formal procedures gives leeway to individual HR officers. This makes the process vulnerable to external influences and some of the

\footnotetext{
${ }^{2}$ In reality, Stage One is intertwined with the registration process, since applicants are allowed to provide the background information and take tests in any order they wish. However, a negligibly small number of applicants move to tests before submitting background information.
} 
firm's current agents seize the opportunity. Their typical intervention takes the form of an electronic recommendation such as the following: ${ }^{3}$

"I am writing regarding My niece, Kim Johnson. She talked to Mary on thursday and was told that she would process her application; someone named (lola or lena) would be calling her on friday or monday. She is still waiting to here from her. Kim's im is kim@Yahoo.com. Thanks for passing the message along."

As the next two examples suggest, some agents make an explicit pitch on behalf of their protégé while others take a seemingly neutral stand:

"Hi Dana....

Good news! I got a new computer this weekend, and as you can see by my weekend, things are working out great! You should be seeing a lot more of me! :-)

Secondly, I wanted to let you know that I have referred 2 people to VCC. One is a friend I have known since 5th grade and the other is my mother. Nina Eider applied a little over a week ago and hasn't heard anything yet, and my mother, Sylvia Morgan, just applied today. I know there isn't a referral program or anything, but was hoping that making you aware of it might help in some way....especially for my mother. Things are pretty rough for my parents financially and I think this would be a great answer for them.

They are both very reliable and ethical people and I think they would be good additions to the VCC team. I know they are both anxious to begin their home based businesses. Thanks so much for your time, and have a wonderful day!

Anna Morgan"

"So it turns out that Kathy's daughter is applying to become a VCC agent. She passed all the tests but hasn't heard anything for 3 weeks. I told her to ask you guys to push her through, but she's adamant that Ellen (her daughter) is to receive NO special treatment.

Whatever. Her name is Ellen Norton. She used to work in the development group for VCC, but her app still may not catch your attention. Can you guys pass her through? Don't tell Kathy ;-)"

As one can see from these recommendations, getting attention from HR personnel poses a challenge for referrers. As the last message suggests, the VCC's HR personnel treat such attempts favorably, in particular, since the agreement to screen does not commit them to a

\footnotetext{
${ }^{3}$ To preserve the anonymity of the firm and agents, we substitute fictional names for the real ones.
} 
positive recruitment decision. In our interviews with HR personnel, all of them claimed that the firm does not treat referrals differently and, in fact, does not pay attention to recruitment sources when deciding whether to approve a particular application. Such claims are consistent with the arm's-length employment relationships the firm establishes with its sales agents. Recently the firm realized that hiring through referrals becomes an impediment for the geographic diversification of its labor force. A substantial portion of the sales agents reside in Florida and Texas and therefore are at high risk of disruption during hurricane season. They also tend to go to church at the same time on Sunday mornings, which happens to be a popular shopping time.

If an application is approved, the HR department sends to the applicant some paperwork and directs her to assemble computer equipment and to sign up for telecommunication services necessary to perform the functions of a sales agent. Since the agent fully controls the process at this stage, Stage Four, which we call Agent Creation, it can be characterized as a self-selection stage.

On Stage Five, the training stage, the candidate goes through on-line training which consists of taking quizzes and making two sales of real products to real callers. When the sales are completed, the candidate is certified and becomes a full-fledged sales agent for the VCC. The HR department has no means to intervene in this process or influence its outcome, and therefore the stage fits into the objective selection category. ${ }^{4}$

To summarize, the five stages of the recruitment process cover all the three types of selection stages introduced in the previous section. Passing the Reading and Logic Tests and

\footnotetext{
${ }^{4}$ In principle, a referrer may complete the training on her behalf, although in practice it is highly unlikely. At the end of the day, the protégé is the one who needs to make a living, since there is no reason why the referrer may want to work under another name at the same VCC. Moreover, the VCC punishes severely for misrepresentation, i.e., logging in its system under another agent's ID.
} 
Training constitute objective selection; taking the Reading and Logic Tests, taking the Voice Test, and Agent Creation represent self-selection; finally, the Approval stage is an instance of subjective selection.

The VCC promotes sales jobs entirely over the Internet in a passive mode (cf., Marsden and Gorman 2001, Yakubovich 2006). It does not advertise them, but instead relies on word-ofmouth and a variety of websites known to be visited by appropriate audiences, such as at-home workers, stay-at-home mothers and people with disabilities. One of the items in the application questionnaire asks the applicant to state how she found out about the job and, if she was referred internally, the name of the sales agent who referred her. We use this piece of information to identify the recruitment channel.

\section{DATA AND METHOD}

\section{Data}

We analyze the VCC's complete database of applications for the position of sales agent submitted between September 2004 and February 2005. The database contains 14,843 records of everyone who started the 5-stage certification process. Applicants from the states of New York, California, Oregon, Washington, Alaska, and Hawaii are automatically deemed unqualified because of state laws that limit a firm's ability to utilize independent contractors. After removing these applicants, the sample size becomes 13,387. 190 applicants were returning agents. Of the remaining applicants, 22 individuals previously convicted for financial crimes are also rejected by the VCC and therefore excluded from the analysis. 227 applicants did not officially submit their applications, because they did not click the submit button, and therefore have never been processed. Further, 328 records cannot be analyzed because they have missing values for some 
variables of interest (gender, ethnicity, income). The company considers only those who provide all the required background information. 3,612 applicants failed to do so which leaves us with 9,008 cases available for analysis.

\section{The Dependent Variables}

Our research questions require a dependent variable for each stage of the recruitment process. The Reading and Logic Tests stage includes two selection steps and therefore are represented by two dependent variables. The dependent variable for each selection step is a dummy coded $0 / 1$ : (1.1) reading and logic tests taken, (1.2) reading and logic tests passed; (2) voice test taken; (3) application approved; (4) agent created; (5) training completed.

Since a candidate is rejected after the first failure, "taking both tests" means that a candidate either took both tests or took one test, failed, and therefore was not allowed to take the second test. In other words, the variable 'reading and logic tests taken' is equal to zero only when an applicant voluntary decided to not take a test. Accordingly, the variable 'reading and logic tests passed' is defined for the applicants who took both tests in the sense just explained. In a similar fashion, the variable 'voice test taken' is defined for those who passed the reading and logic tests, the variable 'agent approved' for those who passed all the tests, the variable 'agent created' for those who were approved, and finally, the variable 'training completed' for those who passed the preceding Agent Creation Stage. Thus, we have six dependent variables defined on a set of nested samples. We discuss how to model them in the Statistical Models section below. 


\section{The Independent Variables: Hiring Channel and the Referrer's Performance}

A closed-end question on the VCC application form asks a candidate how she found out about the job and offers the choice among six mutually exclusive answers: another agent, friend, job ad, bulletin board, chat room, and other. Since the firm does not advertise the job in traditional mass media, we combine "job ad," "bulletin board," and "chat room" into one category "the Internet" and treat it as a reference group.

The distinction between the two types of personal contacts, "agent" and "friend," is important. The former is a proper referrer who possesses information about the employer and can influence the recruitment process. Our conversations with the VCC's HR personnel suggest that the category "friend" is heterogeneous. Mainly, it includes people unaffiliated with the VCC who learned about the job from others or over the Internet and represent essentially another market channel, the only difference being that they target a specific person rather than broadcast information widely. In a small number of cases, the friend can be a staff member of the VCC whose influence on recruitment is stronger than that of sales agents. We consider it as a distinct channel for the purpose of this analysis and assign to it a separate dummy variable.

An applicant who indicates that she was referred to the job by an agent is supposed to put the name of the agent on the application form. We coded each agent by the individual agent $\mathrm{D}$ assigned by the VCC, which allowed us to link these data to performance variables. We measure each referring agent's performance by the utilization rate. Because the agent is paid a fixed rate per minute on the phone, the utilization rate is proportional to the hourly wage, which is not perfect but certainly an adequate indicator of the agent's performance in our setting. Essentially, it measures the agent's fit to the job. The utilization rate varies with the overall demand for the VCC's services, and therefore we construct the performance variable as relative performance by 
dividing the utilization rate of the focal agent for a two-week pay period by the mean utilization rate over the same period and averaging it over all the pay periods worked by the agent during the observation window of our study. 388 agents became referrers before they started working themselves; we combine them in one group labeled "unrated agents."

\section{Control Variables ${ }^{5}$}

To control for the factors that affect a job candidate's progression through the recruitment stages, we code the background information provided on the application. Three dummies - "university" and "advanced degree" with "secondary school" as a reference category - capture candidates' education level. Relevant skills are measured by the dummies "call center experience" and "telemarketing experiences," and by the continuous variable "sales experience" coded in six twoyear increments: $1-2$ years, $3-4,5-6,7-8,9-10$, more than 10 years. The overall job experience is measured by the number of jobs the applicant has had over her career.

The VCC is particularly interested in recruiting agents with excellent Spanish skills. The dummy variable "excellent Spanish" reflects that concern; it is equal to 1 if the applicant reports excellent spoken and written Spanish.

In accordance with anti-discrimination laws, the VCC is not allowed to solicit information on the gender and race of their job applicants. Since the VCC's sales agents are predominantly women, gender may be an issue for both recruitment and performance (Reskin and McBrier 2000, Fernandez and Sosa 2003). To control for it, we code a dummy "female" from a respondent's first name.

\footnotetext{
${ }^{5} \mathrm{~A}$ concise dictionary of all the variables used in the analysis is in Appendix.
} 
To control for race, we use as proxies the percentages of Blacks, Hispanics, and Asians in the zip code area where the agent resides. We also take into account the area's overall economic prosperity and job opportunities by measuring its per capita income. The zip code-level variables come from the 2000 US Census data.

Since the VCC is concerned about the geographic diversification of its agent pool, an applicant's chances of passing the Approval stage may be affected by the number of available agents and other applicants from the same state in the same time period. To control for this situation we construct a variable which counts the number of active agents from the same state at the time when the application is screened for approval.

\section{Statistical Models}

Our dependent variables are observed on progressively smaller subsamples of the original pool of applicants; for those who fail the previous stage, the value of the dependent variable for the following stage is undetermined. This well-known sample selection problem can lead to biased conclusions about the effects of specific variables. For example, to properly evaluate the relationship between referrals and the likelihood of successfully passing the training stage, the VCC would need to allow all the applicants to enter the training stage. Instead, only those who become agents may go into training. To the degree in which the selection process removes less capable applicants, whether referred or not, the survivors should be more uniformly qualified and therefore any advantage of referrals, if it existed, should decline. At the extreme, an analysis of surviving referrals will lead us to the false conclusion that they are equally qualified with nonreferrals. 
To address this problem, we estimate a regression model with selection. Basically, it consists of two models. The first is a selection model of an applicant's chances to proceed to the stage under consideration; the second one is the probit model that estimates the applicant's chances to succeed at that stage. Both models are estimated simultaneously using the fullinformation maximum likelihood method which provides consistent and asymptotically efficient estimates for all the parameters (StataCorp 2003: 75-84).

The variable "performance of a rated agent" is defined only in those cases when the hiring channel is an agent whose performance can be rated, i.e., when the agent has been working for at least one two-week pay period before referring the applicant. At the same time, in order to obtain the effect of a referral, we have to estimate our models for all the applicants, whether they are recruited with the help of a rated agent or not. This can be done if the dummy variable $\mathrm{X}_{1}$ for a rated agent as a hiring channel and the continuous variable $\mathrm{X}_{2}$ for the performance of a rated agent are included in a model in the following way:

$$
a \mathrm{X}_{1}+b \mathrm{X}_{1} \mathrm{X}_{2}=\left(a+b \mathrm{X}_{2}\right) \mathrm{X}_{1},
$$

where $\mathrm{a}$ and $\mathrm{b}$ are estimated coefficients. When $\mathrm{X}_{1}$ is equal to 0 , i.e., when the applicant is not referred by a rated agent, $\mathrm{X}_{2}$ can take any finite value, since the product $\mathrm{X}_{1} \mathrm{X}_{2}$ is equal to 0 anyway. The right-hand side of the equation above shows that this specification fits exactly the propositions we are testing. Namely, it suggests that the effect of a referral expressed as $\left(a+b \mathrm{X}_{2}\right)$ varies with the referrer's performance $\mathrm{X}_{2}$.

\section{RESULTS}

Table 1 contains the descriptive characteristics of the variables included in the analysis. It is split into two parts, $\mathrm{A}$ and $\mathrm{B}$, for categorical and continuous characteristics, respectively. 
Tables $1 \mathrm{a}$ and $1 \mathrm{~b}$ about here

As Table 1a shows, 9008 job seekers completed an application form on the VCC's website and thereby initiated the recruitment process. More than $80 \%$ of them are women, which is consistent with other evidence that work at home attracts primarily females, stay-at-home mothers in particular. More than two thirds of the applicants hold university degrees and another $7 \%$ advanced degrees, which is a high level of education for a sales agent job. The average applicant comes from an area with about $\$ 20,000$ annual income per capita. The applicants appear well qualified for the job. More than half of them have worked for call centers before, slightly less than half have telemarketing experience, and the average tenure in sales is about 3 years.

About $24 \%$ of the applicants found out about vacancies from a sales agent currently working for the firm; another $24.8 \%$ received the same information from a friend who is not an agent. Thus, $48.8 \%$ of the applicants learned about the job through personal contacts, which is remarkably similar to numerous previous studies (for review, see Granovetter 1995, Marsden and Gorman 2001). As job candidates progress through the hiring stages, the proportion of those referred by other agents slowly but steadily increases. The proportion of those who learn about the job from friends who are not agents fluctuates around the $25 \%$ mark while the percentage of those who get job information from the Internet gradually decreases from $35.9 \%$ at the Reading and Logic Tests Stage to $26.1 \%$ at the Training Stage. The category "other" is responsible for about $14 \%-15 \%$ of candidates, which is significant for a residual category. We do not have additional information to decompose it further. 
As one could expect, the mean performance of rated agents is close to one, since a referring agent's performance is, essentially, her utilization rate divided by the average utilization rate (although the averaging is done within each pay period rather than over the whole observation period of the study). An interesting point is that the mean performance gradually increases from 0.901 .1 as the recruitment process progresses from one step to the next. This suggests that at least on the descriptive level, a referrer's performance is positively related to her protégé's chances to succeed.

Table 2 shows the applicants' chance of succeeding across the stages of the recruitment process by selected individual characteristics. Men do slightly better on tests, although this does not help them at the critical Approval and Training Stages where women are more successful. Not surprisingly, higher educated people do better on the reading and logic tests. However, they look slightly overqualified for the job on the Training Stage where candidates with secondary education are more successful than those with higher and advanced degrees.

Table 2 about here

The transition rates by hiring channel shed first light on the main theme of the paper. We see that through all the steps of the recruitment process but Approval the applicants referred by other experienced agents do much better than anybody else. We carry out regression analysis to find out whether this advantage is still present when other factors are controlled for and whether it varies by the performance of the referrer. It should also help us understand the exceptional status of the Approval Stage. Table 3 shows the coefficient estimates for the models with the variable for the referrer's performance included; Table 4 shows the coefficients for hiring channels when referring agents are not differentiated by their performance.

Tables 3, 4 about here 
Some effects of the control variables shed light on the inner workings of the recruitment process at the VCC. Despite being less likely to pass the Reading and Logic Tests, female applicants are given a priority by the HR staff on the Approval Stage. The inconsistency between the objective criterion and subjective opinion more likely indicates that the tests are not comprehensive measures of all the job requirements rather than an evidence of the HR personnel's bias.

A higher level of education helps the applicants with the reading and logic tests but becomes irrelevant as the recruiting process unfolds, which is not surprising, since it is not a prerequisite for a sales agent. Call center experience makes a difference on all the stages but the last two. Telemarketing experience does not add much on any of the stages. Sales experience is highly desirable, and therefore it is not surprising that it plays a significant role on the Approval stage. The negative effect of the number of the current agents in the applicant's state on Approval reflects the VCC's concern about the geographic diversity of the agent population.

Following the logic of our theoretical arguments, we look at the effects of referrals on self-selection steps of the recruitment process: Test Taking, Voice Test, and Agent Creation. In all these cases, the estimated coefficient for the variable Agent in Table 4 is positive and statistically significant. As Proposition 1 claims, referred applicants are more likely to self-select into continuing the recruitment process. The findings in Table 3 reveal that on two self-selection stages, Test Taking and Agent Creation, the likelihood of passing increases with the referrer's performance. For example, as shown on Figure 1, the impact of a referring agent whose performance is twice as high as the average performance is more than double the impact of a referring agent whose performance is at the lower end ( 835 coefficient versus .361$)$. Similar 
patterns appear on Figures 3 and 5 for the Voice Test and Agent Creation Stages, although the slope of the line is not statistically significant for the former.

To test Proposition 2, we interpret the effects of a referrer's performance on the two objective steps: Test Passing and Training. On the Test Passing step, an applicant is required to score at least 60 points (out of 100 ) on two different tests which measure her reading and analytical abilities. As shown in Table 3, the Rho coefficient has a high value of .948 and is statistically significant which implies that the probit model with selection is superior to the conventional probit model. The estimates show that an applicant referred by a current agent is not better than an Internet applicant but that an applicant from the other channels fares significantly worse. One plausible explanation is that it is not necessarily the difficulty of the test per se which prevents applicants referred by non-agent friends from scoring well, ${ }^{6}$ but it may be their unfamiliarity with Internet based tests. Internet applicants are probably computer savvy, and for a person referred by an agent, the gap can be closed if the agent explains to the applicant how the computer-based application works.

For the Training Stage, the probit model with selection does not improve the fit in comparison with the conventional probit model (the $R$ ho coefficient is insignificant) and the estimates of the coefficients slightly vary in magnitude but not in the significance level between the models. In accordance with Proposition 2, Table 3 shows that the likelihood of passing the Training Stage increases with the referrer's performance. Figure 7 illustrates the pattern of the increase. Low performing referrers do not make any difference. As the referrer's relative utilization rate reaches .8 , the effect of the referral on the applicant's success in training becomes

\footnotetext{
${ }^{6}$ Our interviews with the VCC's HR personnel and observations of the company's operating procedures suggest that the tests are not designed to precisely identify "certifiable" candidates. They are purposefully designed to be pretty liberal and to reject only apriori weak and unmotivated applicants.
} 
statistically different from zero. In substantive terms, the impact of the highest performing referrers is almost double the impact of medium performing referrers. Thus, Proposition 2 holds on the Training Stage.

Finally, we look at the subjective Approval Stage. As shown in Table 3 (column 4), the likelihood of an applicant being approved increases with the referrer's performance. Thus, the subjective process of approval is pretty much aligned with the objective stages with regard to the treatment of referrals; being referred per se does not make a difference, the performance of the referrer does matter. In particular, as Figure 4 shows, applicants referred by low performing agents are more likely to be rejected than Internet applicants; the negative effect persists until the referrer's relative utilization rate reaches 0.4 .

\section{DISCUSSION AND CONCLUSIONS}

Our study extends the literature on social networks in recruitment to the new domains of virtual organizations and independent contractors. These domains are characterized by an arm's-length relationship between the firm and its labor force, competition among workers, the firm's generally passive attitude towards recruitment and ignorance of the channels through which it takes place, and workers' ambivalence regarding loyalty to the employer and the quality of the applicants they refer. The fact that even under such circumstances networks remain salient and referrals are beneficial to the employer nicely illustrates the structural side of networks' role in the labor market, independent of the interests and motivations of the parties involved. Referrals still make a difference because they are driven by a number of social mechanisms beyond the firm's and workers' control. In particular, social homophily and information exchange between referrers and job candidates are at work, no matter how actively the firm shapes its relationship 
with the labor force and its pool of applicants. Since a detailed large-scale representative study of recruitment across many diverse organizations is still infeasible, a case-by-case approach to enlarging the scope and testing the limits of our theories is the second best option whose promise the paper demonstrates.

While a number of recent studies that pursue this strategy document advantages of referrals (e.g., Fernandez et. al. 2000, Petersen et. al. 2000), they cannot tell whether these advantages result from objective strengths of referrals, their motivation and persistence, or recruiting managers' subjective belief in their superiority. The virtual organization of the recruitment process allows us to separate these factors. We find robust evidence that referrals are more persistent through the stages when the applicants must decide themselves whether to continue. At the same time, we also find support for the assertion that not all referrals are objectively better candidates: only the referrers of relatively high-performing agents are more likely to complete the training which is as close to actual performance as one can reach within the recruitment process. This finding is another contribution of the paper made possible by the extensive trail of accurate electronic data that a virtual organization offers. The fact that referrals do not do significantly better on the Reading and Logic Tests does not invalidate our conclusions, as the tests are designed to screen out the weakest candidates rather than to find the strongest ones.

Finally, we shed new light on the subjective judgments of HR personnel by showing that referrals attract their attention and offering some anecdotal evidence on referrers' exercise of influence at the VCC. Although attracting attention is not identical to being approved, our analysis suggests that screening is the key stage in the VCC's recruitment process and, most likely, in any Internet-based recruitment. If the barriers to submitting an application are low, HR 
personnel risk being overwhelmed by applicants. As a result, waiting for screening may take months, as is the case at the VCC, and therefore referrers' ability to reduce the waiting period presents a critical advantage. From the HR personnel's perspective, paying attention to referrals is generally warranted, if only because they do better on the Training Stage, which is as close to performance as we can get with the data at hand. However, it also makes sense to expedite the screening of highly qualified individuals who are not referred, since our analysis suggests that they are likely to lose interest in the position if not contacted quickly enough.

More generally, our analysis shows that to control pervasive self-selection, practitioners of online recruitment should proceed expeditiously or risk losing the most attractive applicants. In the long run, the continuous disappointment of qualified candidates as well as excessive numbers of unqualified ones may become the primary factor that will turn on-line recruitment into another formal channel with low reputation. ${ }^{7}$

The Bureau of Labor Statistics' 2001 Current Population Survey finds that about 12.5 million workers, or only $9.4 \%$ of the labor force, practice alternative forms of employment as independent contractors, on-call workers, temporary help agency workers, and contract company workers (Bureau of Labor Statistics 2001). This raises the concern about too narrow a scope of our results. Although any definite claims are impossible without additional research, it would be a mistake to rule out generalizations completely. As restructuring and downsizing become a way of life for American firms, security, in-kind benefits, and career trajectories traditionally offered by long-term employment relationships are being left in the past (Barker and Christensen 1998, Capelli 1999). As a result, even traditional forms of employment become driven by competitive

\footnotetext{
${ }^{7}$ The results of our research which are not reported here show that the longer it takes the VCC to screen an applicant, the more likely it is that the applicant will refuse to proceed to the Agent Creation Stage because she is not interested in the job anymore. This is particularly true for better qualified candidates.
} 
forces which erode the reputational concerns and loyalty typically associated with such forms. The experiences of independent contractors may teach us something about traditional employment relationships as well.

By the same token, independent contractors may not exactly be the free agents the literature portrays them to be. For example, the VCC maintains a chat room where sales agents go to not only to resolve technical problems but to engage in social interactions with the colleagues who work with them on the same shift. Relationships forged in such interactions may strengthen agents' group identity and their attachment to the workplace. Only future research can tell if such processes take place and how they shape the firm's recruitment.

In addition to virtual organization and independent contractors, another important contextual detail of the paper's setting is the completely informal role of the recruitment through networks at the VCC. So far, the best empirical studies on the topic rely on data accumulated as a byproduct of employers' formal referral policies. Fully aware of the utility of social networks in recruitment, employers treat them as a key component of such policies. Social networks become a tool for screening for talent and reaching out to potential job candidates who otherwise would not apply (Breaugh and Mann 1984; Fernandez and Weinberg 1997; Fernandez, Castilla, and Moore 2000; Petersen, Saporta, and Seidel 2000). Paradoxically, researchers manage to shed new light on informal structures, only to the degree in which those are formalized. Our study benefits from the fact that any activity on the Internet leaves a record, whether or not the actors desire one. The employer we study neither rewards its sales agents for referrals nor advertises its vacancies. We empirically show that in this more informal setting, referrals maintain an important labor market role, which brings the literature on referrals closer to its origins in the literature on organizations' embeddedness in informal social networks. 


\section{BIBLIOGRAPHY}

Barker, Kathleen and Kathleen Christensen (Editors). 1998. Contingent Work. American

Employment Relations in Transition. Ithaca, NY: Cornell University Press.

Breaugh, J.A. and R.B. Mann. 1984. "Recruiting Source Effects: A Test of Two Alternative

Explanations." Journal of Occupational Psychology. 57: 261-267.

Bureau of Labor Statistics. 2001. "Contingent and Alternative Employment Arrangements."

Economic News Releases. http://bls.gov/news.release/conemp.nr0.htm.

Capelli, Peter. 1999. The New Deal at Work. Managing the Market-Driven Workforce. Boston, MA: Harvard Business School.

Castilla, Emilio J. 2005. "Social Networks and Employee Performance in a Call Center." American Journal of Sociology 110(5):1243-83.

Crozier, Michel. 1964. The Bureaucratic Phenomenon. London: Tavistock.

Eliott, James R. 2001 “Referral Hiring and Ethnical Homogeneous Jobs: How Prevalent is the Connection and for Whom?" Social Science Research. 30: 401-25.

Fernandez, Roberto M. and Emilio J. Castilla. 2001. "How Much Is That Network Worth? Social Capital in Employee Referral Networks." In Social Capital: Theory and Research. Edited by Nan Lin, Karen Cook, and Ronald S. Burt. New York: Aldine de Gruyter.

Fernandez, Roberto M., Emilio Castilla, and Paul Moore. 2000. "Social Capital at Work: Networks and Employment at a Phone Center." American Journal of Sociology $105(5): 1288-356$

Fernandez, Roberto M. and Lourdes Sosa. 2004. "Gendering the Job: Networks and Recruitment at a Call Center." Working paper. 
Fernandez, Roberto M., and Nancy Weinberg. 1997. "Sifting and Sorting: Personal Contacts and Hiring in a Retail Bank." American Sociological Review 62(6): 883-902.

Hagan Jacqueline M. 1997. "Social Networks, Gender, and Immigrant Incorporation: Resources and Constraints." American Sociological Review 63: 55-67.

Granovetter, Mark. 1995[1974]. Getting a Job: A Study of Contacts and Careers. Cambridge, MA: Harvard University Press.

Jarillo, J.Carlos. 1993. Strategic Networks: Creating the Borderless Organization. Oxford: Butterworth-Heinemann.

Jones, Caroline. "Teleworking: the Quiet Revolution (2005 Update).” Gartner Group Publication \#G00122284, available from www.gartner.com

Kunda, Gideon, Stephen R. Barley, and James Evans. 2002. "Why Do Contractors Contract? The Experience of Highly Skilled Technical Professionals in a Contingent Labor Market." Industrial and Labor Relations Review 55(2): 234-61.

Leicht, Kevin, T. and Jonathan Marx. 1997. "The consequences of informal job finding for men and women." Academy of Management Journal 40 (4): 967-987

Lin, Nan, Walter M. Ensel, and John C. Vaughn. 1981. "Social Resources and Strength of Ties: Structural Factors in Occupational Status Attainment." American Sociological Review, 46 (4): $393-405$

Lin, Nan. 2003. "The Invisible Hand of Social Capital." Working paper.

Marsden, Peter V. and Gorman, Elizabeth H. 2001. "Social Networks, Job Changes, and Recruitment." Pp. 467-502 in Sourcebook of Labor Markets: Evolving Structures and Processes. Edited by Ivar Berg and Arne L. Kalleberg. New York: Kluwer Academic / Plenum Publishers. 
Myers, Charles A. and George P. Shultz. 1951. The Dynamics of a Labor Market, New York: Prentice Hall.

McPherson, Miller, Lynn Smith-Lovin, and James M. Cook. 2001. "Birds of a Feather: Homophily in Social Networks". Annual Review of Sociology 27:415-44

Montgomery, James D. 1991, "Social Networks and Labor Market Outcomes", American Economic Review 57: 586-96

Mouw Ted. 2003. "Social Capital and Finding a Job. Do Contacts Matter?" American Sociological Review 68: 868-98

Petersen, Trond, Ishak Saporta, and Marc-David L. Seidel. 2000. "Offering a Job: Meritocracy and Social Networks." American Journal of Sociology 106(3): 763-816.

Pfeffer, Jeffrey and Robert Sutton. 2000. The Knowing-Doing Gap: How Smart Companies Turn Knowledge into Action, Cambridge, MA: Harvard Business School Press.

Rees, Albert and George P. Shultz.1970. Workers and Wages in an Urban Labor Market, University of Chicago Press

Reskin, Barbara F. and Debra Branch McBrier. 2000. "Why Not Ascription? Organizations' Employment of Male and Female Managers." American Sociological Review 65: 210233.

StataCorp. 2003. Stata Statistical Software: Release 8.0. College Station, TX: Stata Corporation. Ullman, Joseph. C. 1966. "Employee Referrals: Prime Tool for Recruiting Workers." Personnel Psychology 43: 30-35

Yakubovich, Valery. 2006. "Passive Recruitment In the Russian Urban Labor Market." Work and Occupations. Forthcoming. 


\section{Table 1a: Frequency Distribution for Selected Categorical Characteristics of Job Candidates}

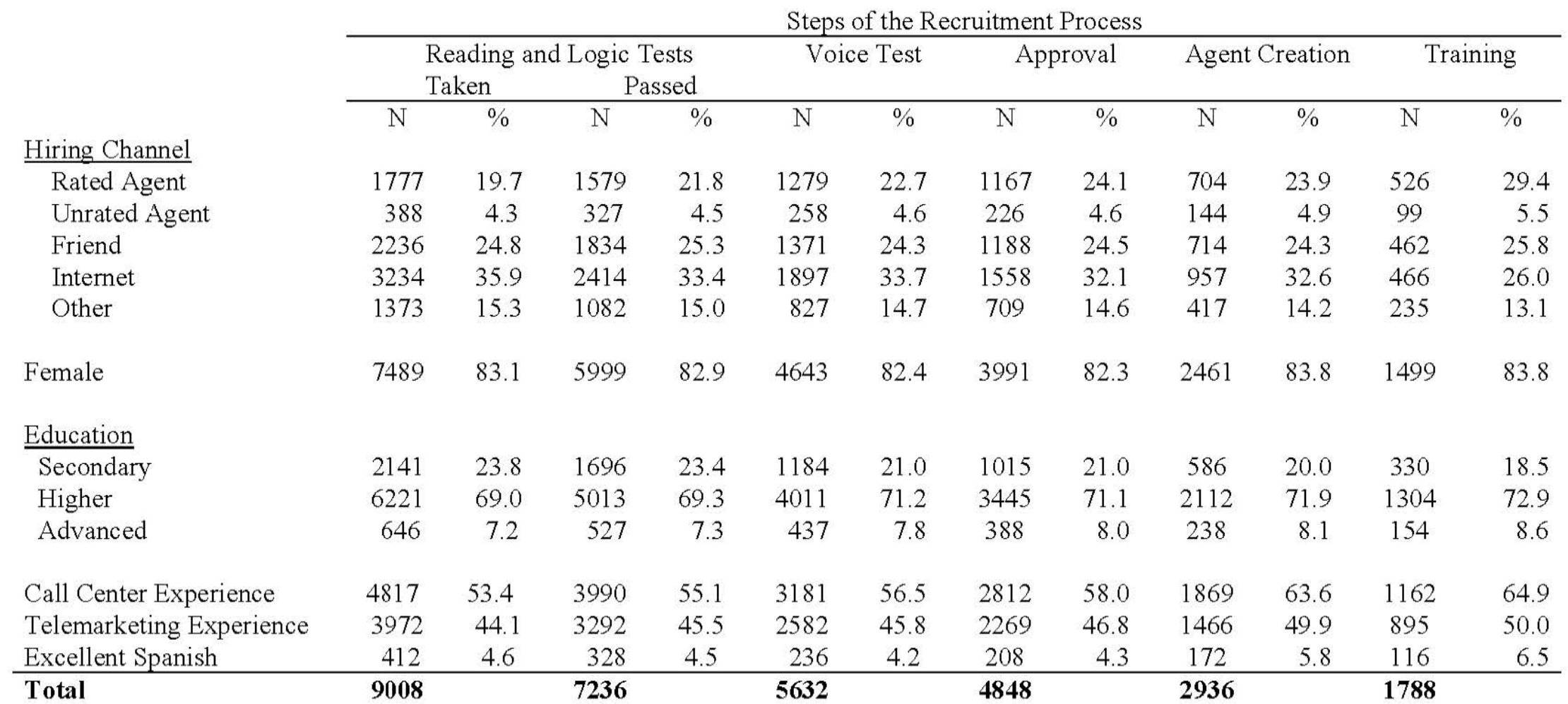


Table 1b: Means and Standard Deviations for Selected Continuous Characteristics of Job Candidates

\begin{tabular}{|c|c|c|c|c|c|c|}
\hline & \multicolumn{6}{|c|}{ Steps of the Recruitment Process } \\
\hline & \multicolumn{2}{|c|}{ Reading and Logic Tests } & \multirow[t]{2}{*}{ Voice Test } & \multirow[t]{2}{*}{ Approval } & \multirow[t]{2}{*}{ Agent Creation } & \multirow[t]{2}{*}{ Training } \\
\hline & Taken & Passed & & & & \\
\hline \multirow{2}{*}{ Performance of Rated Agent } & .9 & .9 & 1.0 & 1.0 & 1.0 & 1.1 \\
\hline & .4 & 4 & .4 & .4 & .4 & .4 \\
\hline \multirow[t]{2}{*}{ Sales Experience } & 3.1 & 3.1 & 3.1 & 3.2 & 3.5 & 3.6 \\
\hline & 3.3 & 3.3 & 3.3 & 3.3 & 3.3 & 3.4 \\
\hline \multirow[t]{2}{*}{ Previous Job Experience } & 1.1 & 1.1 & 1.1 & 1.1 & 1.1 & 1.1 \\
\hline & 1.1 & 1.1 & 1.1 & 1.0 & 1.0 & 1.0 \\
\hline \multirow[t]{2}{*}{ Asian (\%) } & 1.8 & 1.8 & 1.7 & 1.7 & 1.7 & 1.7 \\
\hline & 2.8 & 2.8 & 2.7 & 2.7 & 2.7 & 2.8 \\
\hline \multirow[t]{2}{*}{ Black (\%) } & 15.5 & 15.8 & 15.5 & 15.9 & 15.4 & 15.7 \\
\hline & 22.1 & 22.2 & 21.9 & 22.3 & 21.8 & 21.9 \\
\hline \multirow[t]{2}{*}{ Hispanic (\%) } & 10.5 & 10.7 & 10.6 & 10.9 & 11.4 & 11.5 \\
\hline & 17.2 & 17.3 & 17.2 & 17.6 & 18.3 & 18.3 \\
\hline \multirow[t]{2}{*}{ Whites (\%) } & 69.9 & 69.3 & 69.8 & 69.0 & 68.9 & 68.4 \\
\hline & 27.2 & 27.4 & 27.3 & 27.6 & 27.7 & 27.9 \\
\hline \multirow[t]{2}{*}{ Income (in $\$ 1000$ ) } & 20.6 & 20.5 & 20.7 & 20.7 & 20.7 & 20.7 \\
\hline & 6.8 & 6.8 & 6.9 & 6.9 & 6.9 & 6.9 \\
\hline Number of Agents from & 195.5 & 201.1 & 199.9 & 204.3 & 181.4 & 197.9 \\
\hline Same State & 203.2 & 204.6 & 205.3 & 208.3 & 186.7 & 194.7 \\
\hline Total & 9008 & 7236 & 5632 & 4848 & 2936 & 1788 \\
\hline
\end{tabular}


Table 2. The Rates of Transition across Steps of the Recruitment Process by Selected Characteristics of the Applicants

\begin{tabular}{|c|c|c|c|c|c|c|c|c|c|c|c|c|}
\hline & \multicolumn{12}{|c|}{ Steps of the Recruitment Process } \\
\hline & \multicolumn{4}{|c|}{ Reading and Logic Tests } & \multirow{2}{*}{\multicolumn{2}{|c|}{ Voice Test }} & \multirow{2}{*}{\multicolumn{2}{|c|}{ Approval }} & \multirow{2}{*}{\multicolumn{2}{|c|}{ Agent Creation }} & \multirow{2}{*}{\multicolumn{2}{|c|}{ Training }} \\
\hline & & Taken & & issed & & & & & & & & \\
\hline & $\begin{array}{c}\text { Enter } \\
\mathrm{N}\end{array}$ & Pass \% & $\begin{array}{c}\text { Enter } \\
\mathrm{N}\end{array}$ & Pass \% & $\begin{array}{c}\text { Enter } \\
\mathrm{N}\end{array}$ & Pass \% & $\begin{array}{c}\text { Enter } \\
\mathrm{N}\end{array}$ & Pass \% & $\begin{array}{c}\text { Enter } \\
\mathrm{N}\end{array}$ & Pass \% & $\begin{array}{c}\text { Enter } \\
\mathrm{N}\end{array}$ & Pass \% \\
\hline \multicolumn{13}{|l|}{ Hiring Channel: } \\
\hline Rated Agent & 1777 & 88.8 & 1579 & 81.0 & 1279 & 91.2 & 1167 & 60.3 & 704 & 74.7 & 526 & 84.4 \\
\hline Unrated Agent & 388 & 84.2 & 327 & 78.8 & 258 & 87.5 & 226 & 63.7 & 144 & 68.7 & 99 & 74.7 \\
\hline Friend & 2236 & 82.0 & 1834 & 74.7 & 1371 & 86.6 & 1188 & 60.1 & 714 & 64.7 & 462 & 75.6 \\
\hline Internet & 3234 & 74.6 & 2414 & 78.5 & 1897 & 82.1 & 1558 & 61.4 & 957 & 48.7 & 466 & 73.6 \\
\hline Other & 1373 & 78.8 & 1082 & 76.4 & 827 & 85.7 & 709 & 58.8 & 417 & 56.3 & 235 & 74.0 \\
\hline Gender: Female & 7489 & 80.1 & 5999 & 77.3 & 4643 & 85.9 & 3991 & 61.6 & 2461 & 60.9 & 1499 & 77.4 \\
\hline Male & 1519 & 81.4 & 1237 & 79.9 & 989 & 86.6 & 857 & 55.4 & 475 & 60.8 & 289 & 74.4 \\
\hline \multicolumn{13}{|l|}{ Education: } \\
\hline Secondary & 2141 & 79.2 & 1696 & 69.8 & 1184 & 85.7 & 1015 & 57.7 & 586 & 56.3 & 330 & 79.4 \\
\hline Higher & 6221 & 80.5 & 5013 & 80.0 & 4011 & 85.8 & 3445 & 61.3 & 2112 & 61.7 & 1304 & 76.2 \\
\hline Advanced & 646 & 81.5 & 527 & 82.9 & 437 & 88.7 & 388 & 61.3 & 238 & 64.7 & 154 & 78.0 \\
\hline Call Center Experience: Yes & 4817 & 82.8 & 3990 & 79.7 & 3181 & 88.4 & 2812 & 66.5 & 1869 & 62.2 & 1162 & 75.8 \\
\hline No & 4191 & 77.4 & 3246 & 75.5 & 2451 & 83.0 & 2036 & 52.4 & 1067 & 58.7 & 626 & 78.9 \\
\hline Telemarketing Experience: Yes & 3972 & 82.8 & 3292 & 78.4 & 2582 & 87.8 & 2269 & 63.7 & 1466 & 61.1 & 895 & 77.3 \\
\hline No & 5036 & 78.3 & 3944 & 77.3 & 3050 & 84.5 & 2579 & 57.0 & 1470 & 60.7 & 893 & 76.5 \\
\hline Excellent Spanish: Yes & 412 & 79.6 & 328 & 71.9 & 236 & 88.1 & 208 & 82.7 & 172 & 67.4 & 116 & 73.3 \\
\hline No & 8596 & 80.3 & 6908 & 78.1 & 5396 & 85.9 & 4640 & 59.6 & 2764 & 60.5 & 1672 & 77.2 \\
\hline Total & 9008 & 80.3 & 7236 & 77.8 & 5632 & 86.0 & 4848 & 60.6 & 2936 & 60.9 & 1788 & 76.9 \\
\hline
\end{tabular}


Table 3. The Probability of a Job Candidate Completing a Step of the Recruitment Process: Bivariate Probit Model with the Agent - Referrer's Performance as a Predictor, Controlling for Selection at the Previous Steps ${ }^{\dagger}$

\begin{tabular}{|c|c|c|c|c|c|c|}
\hline \multirow[b]{2}{*}{ Type of Selection } & \multicolumn{6}{|c|}{ Steps of the Recruitment Process } \\
\hline & $\begin{array}{c}\text { Tests Taking } \\
\text { Self-Selection } \\
\end{array}$ & $\begin{array}{c}\text { Tests Passing } \\
\text { Objective }\end{array}$ & $\begin{array}{c}\text { Voice Test } \\
\text { Self-Selection } \\
\end{array}$ & $\begin{array}{l}\text { Approval } \\
\text { Subjective }\end{array}$ & $\begin{array}{l}\text { Agent Creation } \\
\text { Self-Selection }\end{array}$ & $\begin{array}{c}\text { Training } \\
\text { Objective }\end{array}$ \\
\hline \multicolumn{7}{|l|}{ Hiring Channel (Internet) } \\
\hline Rated Agent & $.308(.094)^{* * *}$ & $.003(.091)$ & $.190(.117)$ & $-.258(.104)^{* *}$ & $.110(.137)$ & $-.013(.186)$ \\
\hline Performance of Rated Agent & $.263(.090)^{* *}$ & $-.024(.083)$ & $.089(.109)$ & $.202(.099)^{*}$ & $.532(.157)^{* * *}$ & $.486(.191)^{*}$ \\
\hline Unrated Agent & $.333(.080)^{* * *}$ & $-.061(.079)$ & $.126(.096)$ & $.083(.101)$ & $.470(.153)^{* *}$ & $.119(.192)$ \\
\hline Friend & $.247(.039)^{* * * *}$ & $-.171(.040)^{* * *}$ & $.131(.049)^{* *}$ & $-.001(.052)$ & $.360(.079)^{* * *}$ & $.070(.116)$ \\
\hline Other & $.124(.045)^{* *}$ & $-.111(.047)^{*}$ & $.109(.057)$ & $-.075(.056)$ & $.161(.074)^{*}$ & $.045(.112)$ \\
\hline Female & $-.011(.041)$ & $-.097(.042)^{*}$ & $.023(.050)$ & $.160(.046)^{* * *}$ & $.051(.069)$ & $.094(.089)$ \\
\hline \multicolumn{7}{|l|}{ Education (Secondary) } \\
\hline Higher & $.024(.036)$ & $.274(.035)^{* * *}$ & $-.086(.046)$ & $.021(.056)$ & $.105(.082)$ & $-.067(.106)$ \\
\hline Advanced & $.063(.066)$ & $.374(.068)^{* * *}$ & $.010(.084)$ & $-.023(.092)$ & $.192(.133)$ & $-.006(.167)$ \\
\hline Call Center Experience & $.216(.031)^{* * *}$ & $.103(.034)^{* *}$ & $.150(.039)^{* * *}$ & $.289(.072)^{* * *}$ & $.077(.128)$ & $-.024(.127)$ \\
\hline Sales Experience & $.007(.005)$ & $-.005(.005)$ & $.019\left(.006^{* * *}\right.$ & $.031(.007)^{* * x}$ & $.005(.011)$ & $.015(.012)$ \\
\hline Excellent Spanish & & $-.167(.069)^{*}$ & $.110(.097$ & $.891(.114)^{* * *}$ & $-.018(.145)$ & \\
\hline Previous Job Experience & $.062(.015)^{* * *}$ & $.057(.016)^{* * *}$ & & & & \\
\hline Telemarketing Experience & & $-.028(.033)$ & & $.039(.040)$ & $-.047(.053)$ & $.047(.071)$ \\
\hline Agents from Same State $(1,000 \mathrm{~s})$ & & & & $-.976(.107)^{* * *}$ & $.631(.186)^{* * * *}$ & $-.491(.168)^{* *}$ \\
\hline Income & $.004(.051)$ & & & & & \\
\hline Asian & & $-1.099(.519)^{*}$ & & & & \\
\hline Black & & $-.192(.067)^{* *}$ & & & & \\
\hline Hispanic & & $-.111(.088)$ & & & & \\
\hline Constant & $.399(.510)$ & $-.044(.496)$ & $1.156(.072)^{* * *}$ & $.345(.267)$ & $-.099(.665)$ & $.352(.795)$ \\
\hline Sample Size & 9008 & 7236 & 5632 & 4848 & 2936 & 1788 \\
\hline Rho (chi 2) & & $-.948(9.100)^{* * *}$ & $-.867(8.140)^{* *}$ & $-.467(2.490)$ & $-.177(.170)$ & $.169(.190)$ \\
\hline Log Likelihood & -4342.649 & -8083.300 & -8019.486 & -9102.341 & -7315.992 & -5192.880 \\
\hline
\end{tabular}

\footnotetext{
${ }^{\dagger}$ The model for the first step is simple probit. The selection models for the subsequent steps are omitted and available from the authors upon request.
} 
Table 4. The Probability of a Job Candidate Completing a Step of the Recruitment Process: Bivariate Probit Model with the Agent - Referrer as a Predictor, Controlling for Selection at the Previous Steps ${ }^{\dagger}$

\begin{tabular}{|c|c|c|c|c|c|c|}
\hline \multicolumn{7}{|c|}{ Steps of the Recruitment Process } \\
\hline & Tests Taking & Tests Passing & Voice Test & Approval & Agent Creation & Training \\
\hline \multicolumn{7}{|c|}{ Hiring Channel (Internet) } \\
\hline Agent & $.509(.042)^{* * *}$ & $-.027(.042)$ & $.246(.052)^{* * *}$ & $-.052(.076)$ & $.250(.104)^{*}$ & $.103(.146)$ \\
\hline Friend & $.247(.039)^{* * *}$ & $-.171(.040)^{* * *}$ & $.131(.049)^{* *}$ & $-.003(.051)$ & $.187(.074)^{*}$ & $-.066(.095)$ \\
\hline Other & $.124(.045)^{* *}$ & $-.111(.047)^{* *}$ & $.109(.057)$ & $-.076(.055)$ & $.098(.060)$ & $-.012(.101)$ \\
\hline Sample Size & 9008 & 7236 & 5632 & 4848 & 2936 & 1788 \\
\hline
\end{tabular}

${ }^{\dagger}$ Only the coefficient estimates for the hiring channels are shown. The other coefficients are identical to their counterparts in Table 3. 

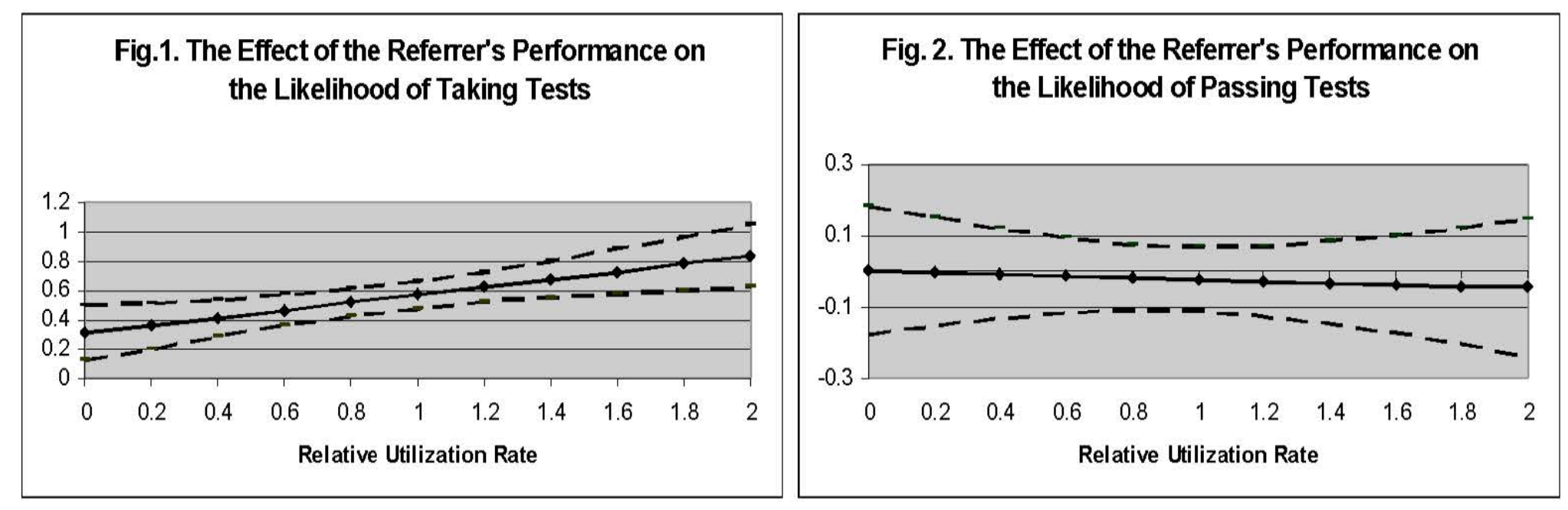

Fig. 3. The Effect of Referrer's Performance on the Likelihood of Taking the Voice Test

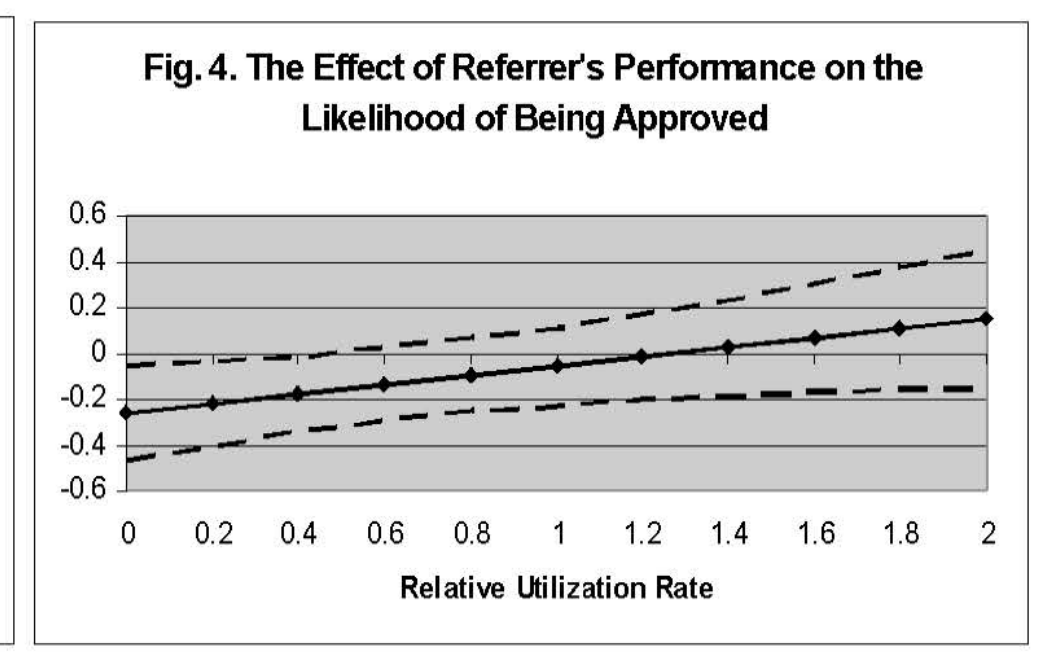



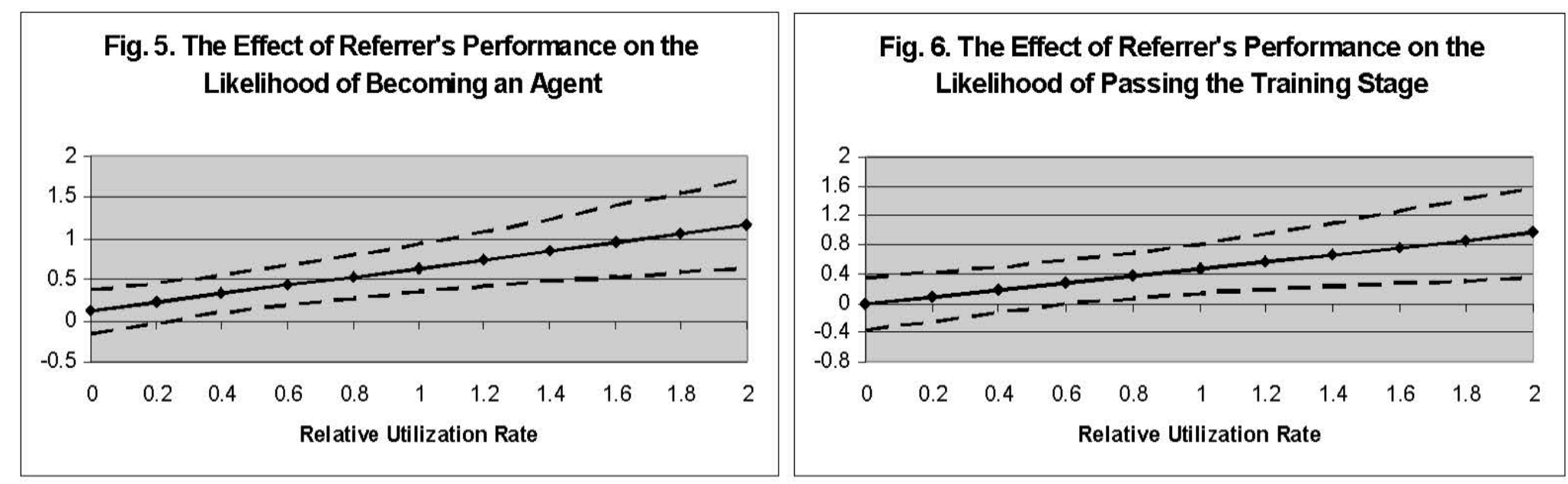
Appendix A

The Dictionary of the Independent and Control Variables

\begin{tabular}{ll}
\hline \multicolumn{1}{c}{ Variables } & \multicolumn{1}{c}{ Definition } \\
\hline $\begin{array}{l}\text { Hiring Channel } \\
\text { Rated Agent }\end{array}$ & 1 if the referrer is a current agent with performance record \\
Unrated Agent & 1 if the referrer is a current agent without a perform. record \\
& $=$ mean relative utilization rate of the agent across pay periods \\
Performance of Rated Agent & 1 if the referrer is a non-agent friend \\
Friend & $=1$ if the referrer is an Internet based channel \\
Internet & $\quad$ chat room, bulletin board, job ad)
\end{tabular}

